\title{
RANCANG BANGUN MESIN PEMINTAL BENANG DENGAN KAPASITAS 3 CONS MENGGUNAKAN SOFTWARE AUTOCAD
}

\author{
ELLYSA KUSUMA LAKSANAWATI ${ }^{1}$, HENDRA HARSANTA ${ }^{2}$, YOGA SAPUTRA ${ }^{3}$ \\ Program Studi Teknik Mesin, Fakultas Teknik, Universitas Muhammadiyah Tangerang \\ Jl. Perintis Kemerdekaan I/33 Cikokol-Tangerang \\ E-Mail : ellysahendri@gmail.com
}

\begin{abstract}
ABSTRAK
Mesin pemintal benang adalah suatu perkakas yang dibuat untuk menggulung benang yang lebih modern dengan penggerak motor listrik untuk mendapatkan waktu yang terbaik, dan efektif agar kapasitas produksinya meningkat dengan proses penggulungan benang dengan menggunakan eksperimen 3cons. Sehingga masyarakat diharapkan dapat meningkatkan produktivitas, kapasitas produksi, dan meningkatkan perekonomian tanpa mengurangi kualitas usaha penggulungan benang dengan adanya mesin ini khususnya benang obras.Mesin ini didesain menggunakan Software AutoCAD, kerangka dasar pada mesin ini memakai model dan tipe kerangka mesin yang sudah ada sebelumnya akan tetapi mesin ini lebih bersifat Portable (mudah dibongkar pasang/dipindahkan). Mesin ini memiliki ukuran yang lebih kecil sehingga dalam pemakaiannya mesin ini tidak memakan tempat dan apabila sudah tidak dipakai, mesin ini bisa dibongkar dan disimpan di dalam box sehingga lebih aman. Dalam proses pembuatannya mesin ini membutuhkan biaya yang cukup hemat dan juga material maupun sparepart yang dipakai dalam pembuatan mesin pemintal benang ini juga bersifat standarisasi pabrik atau mudah ditemukan tanpa memerlukan pengubahan atau modifikasi bentuk dan ukurannya sehingga memudahkan dalam proses penggantian apabila terjadi suatu masalah pada mesin tersebut.
\end{abstract}

Kata Kunci : Mesin pemintal benang; AutoCAD; 3Cons; Portable.

\begin{abstract}
Yarn spinning machine is a tool made to wind more modern yarn with electric motor drive to get the best time, and it is effective to increase production capacity with yarn winding process using 3 cons experiment. So that the community is expected to increase productivity, production capacity, and improve the economy without reducing the quality of the yarn winding business with this machine, especially overlock yarn. but this machine is more portable (easy to disassemble/move). This machine has a smaller size so that in its use this machine does not take up space and when it is not used, this machine can be disassembled and stored in a box so it is safer. In the manufacturing process, this machine requires a fairly efficient cost and also the materials and spare parts used in the manufacture of this yarn spinning machine are also factory standardized or easy to find without requiring changes or modifications to the shape and size so as to facilitate the replacement process if a problem occurs with the machine.
\end{abstract}

Keywords: Yarn spinning machine; AutoCAD; 3Cons; Portable.

\section{PENDAHULUAN}

Mesin penggulung benang tradisional adalah suatu mesin dengan penggerak manual tenaga manusia untuk menggulung benang polyester yang sudah dipilin atau digintir. Seiring perkembangan zaman pada era sekarang ini dan teknologi semakin maju dimana pelaku industri-industri kecil masih ada yang menggunakan dan mempertahankan mesin-mesin tradisional yang menggunakan tenaga penggerak manusia untuk menjalankan usahanya, dan masih belum mau mengganti dengan mesin yang lebih modern penggerak tenaga motor listrik karena faktor - faktor tertentu dari pelaku industri kecil itu sendiri.

Banyak mesin tradisional yang digunakan untuk memproduksi proses penggulungan benang, dimana kalau menggunakan mesin yang penggulung benang tradisional, waktu yang dibutuhkan untuk memproduksi gulungan benang masih lama, dan hasil produksi yang masih belum maksimal mungkin, serta pengoperasian mesin tradisional yang masih belum fleksibel dan efektif. Oleh karena itu dengan melihat berbagai potensi terhadap industri kecil penggulungan benang yang mempunyai peranan penting dalam menggerakkan perekonomian para pengrajin penggulung benang khususnya di Desa Kongsi Baru Kec. Rajeg, Tangerang, Banten. Maka sekarang ini perlu adanya inovasi suatu konsep untuk mengembangkan dan memajukan industri kecil tersebut supaya hasil produksi gulungan benang semakin meningkat tiap bulannya dan perekonomian para pengrajin benang semakin meningkat, dengan cara menciptakan suatu mesin penggulung benang yang lebih modern untuk menggantikan mesin penggulung benang yang masih tradisional. 
Salah satu sumber energi alternatif yang masuk dalam perkembangan teknologi yang semakin maju ialah sumber energi air, dengan ditemukannya alat yang inovatif yaitu turbin dengan tipe turbin pelton yang dapat menghasilkaan energi listrik menggunakan tenaga air. Prinsip kerja turbin air adalah mengkonversi aliran air menjadi daya. Air yang berada pada bak penampung di hisap oleh pompa untuk di alirkan melalui perpipaan yang diberi katup sehingga laju aliran air dapat diatur sesuai dengan keinginan, kemudian diteruskan ke nozzle. Kemudian air yang keluarkan oleh nozzle digunakan untuk memutar sudu turbin yang selanjutnya jatuh kedalam bak penampung agar selanjutnya kembali ke tahap awal sehingga terjadi sirkulasi.

Dalam penelitian ini mencoba untuk merancang suatu mesin penggulung benang yang lebih modern dengan penggerak motor listrik dan kemudian membuatan mesin penggulung benang dengan penggerak motor listrik, untuk mendapatkan waktu yang terbaik, dan efektif agar kapasitas produksinya meningkat dengan proses penggulungan benang dengan menggunakan mesin eksperimen 3cons. Maka penulis menambil judul "Rancang Bangun Mesin Pemintal Benang dengan Kapasitas 3cons Menggunakan Software Autocad.

\section{METODOLOGI PENELITIAN}

Metodologi penelitian ini adalah eksperimen dengan meracang langsung mesing pemintal benang. Diawali dengan pembuatan desain AutoCAD, pembuatan mesin dan analisis mesin.

Pada tahap perancangan mesin pemintal benang diawali dengan pembuatan desian rangka dasar dengan menggunakan software AutoCAD .

Berikut adalah tahap tahap desain dengan menggunakan Software AutoCAD.

1.Buka Software AutoCAD

Pada tahap ini pastikan laptop/PC sudah terinstal software AutoCAD.

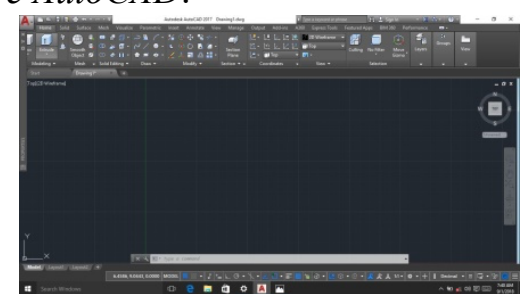

Gambar 1. Layar Utama Software AutoCAD

\section{Ukuran kerangka mesin pandangan atas}

Berikut merupakan ukuran kerangka mesin pemintal benang pandangan atas, depan, dan samping dengan satuan mm.

Kerangka mesin dilihat dari pandangan depan. Panjang besi siku penghubung kaki kanan dan kaki kiri pada kerangka mesin $1300 \mathrm{~mm}$, panjang besi siku penghubung kaki depan dan kaki belakang bagian atas adalah $350 \mathrm{~mm}$, panjang As atas $1200 \mathrm{~mm}$ dan panjang As bawah $1350 \mathrm{~mm}$.

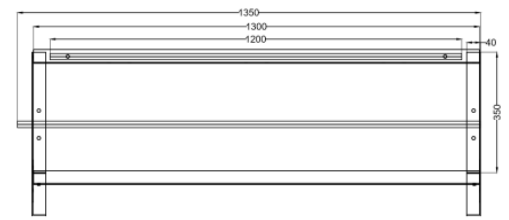

Gambar 2. Kerangka Mesin Pandangan Atas

Pada pandangan ini terlihat panjang besi siku penghubung kaki kanan dan kaki kiri berjumlah 3 pcs, diameter As atas $18 \mathrm{~mm}$, diameter As bawah $19 \mathrm{~mm}$, dan tinggi penyangga As atas $116 \mathrm{~mm}$.

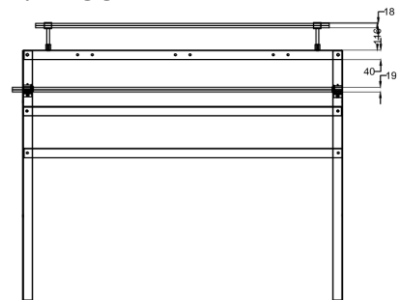

Gambar 3. Kerangka Mesin Pandangan Depan

Kerangka mesin dilihat dari pandangan samping. Panjang besi siku kaki belakang $1050 \mathrm{~mm}$, panjang besi siku penghubung kaki depan dan belakang bagian bawah $420 \mathrm{~mm}$, sudut kemiringan pada kaki depan adalah $98^{\circ}$, jarak antara bagian ujung bearing dengan ujung besi siku depan adalah $90 \mathrm{~mm}$ dan jarak antara bagian ujung bearing dengan ujung besi siku belakang adalah $120 \mathrm{~mm}$,

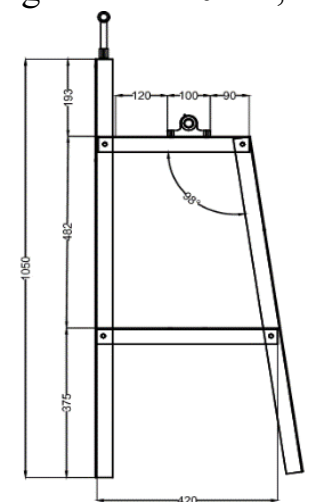

Gambar 4. Kerangka Mesin Pandangan Samping

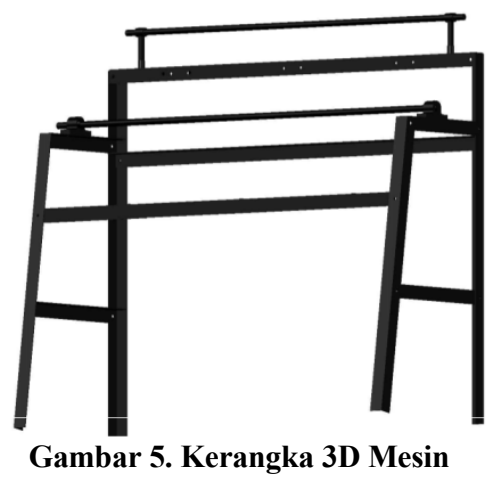


Pada tahap ini mesin yang sebelumnya sudah di desain melalui software AutoCAD selanjutnya akan dibuat secara nyata melalui proses-proses sebagai berikut:

1. Proses Pemilihan material

Pada proses ini material yang akan dipakai untuk kerangka dasar adalah besi siku dengan ukuran $40 \mathrm{~mm} \times 400 \mathrm{~mm} \times 3 \mathrm{~mm}$ dan untuk ukuran baut M10 dan M8.

\section{Proses pemotongan}

Proses ini adalah proses lanjutan setelah pemilihan bahan, pada proses ini besi siku sebagai rangka dasar dipotong sesuai ukuran panjang yang sudah ditentukan sebelumnya yaitu:
a) Uk. $1050 \mathrm{~mm}=2$ batang
b) Uk. $850 \mathrm{~mm}=2$ batang
c) Uk. $350 \mathrm{~mm}=2$ batang
d) Uk. $1300 \mathrm{~mm}=3$ batang
e) Uk. $420 \mathrm{~mm}=2$ batang
f) Uk. $110 \mathrm{~mm}=2$ batang

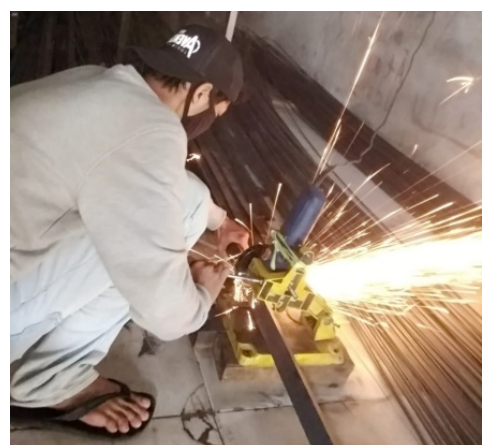

Gambar 5. Proses Pemotongan Material

\section{Proses pengeboran}

Pada proses ini besi siku yang sudah dipotong lalu dilubangi dengan mesin bor dengan diameter lubang $10 \mathrm{~mm}, 8 \mathrm{~mm}, 6 \mathrm{~mm}, 4 \mathrm{~mm}$.

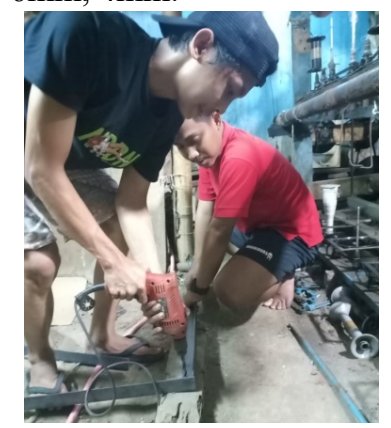

Gambar 6. Proses Pengeboran Material

\section{Proses pengecatan}

Proses pengecatan adalah proses yang bertujuan untuk memberi memberi warna pada alat dan juga untuk mengurangi korosi pada material.

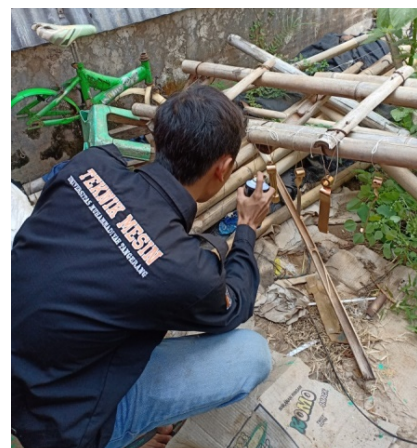

\section{Gambar 7. Pengecatan Komponen Mesin}

Proses ini merupakan proses akhir sebelum uji coba mesin, proses perakitan mesin adalah sebagai berikut.

a. Persiapkan alat dan bahan

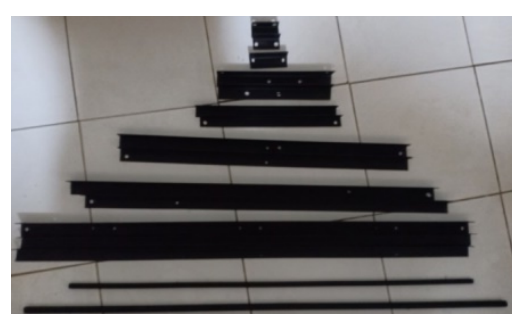

Gambar 8. Material

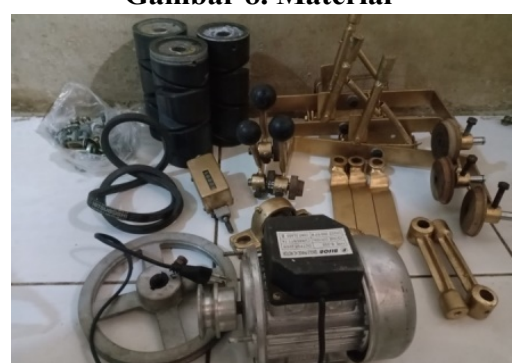

Gambar 9. Komponen - Komponen Mesin

b. Penggabungan part

Penggabungan yang pertama adalah penggabungan antara besi siku dengan ukuran $1050 \mathrm{~mm}, 840 \mathrm{~mm}, 340 \mathrm{~mm}$ dan $420 \mathrm{~mm}$ dengan menggunakan kunci pas uk.

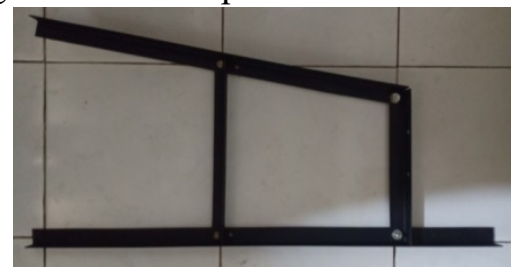

Gambar 10. Kaki Kiri 


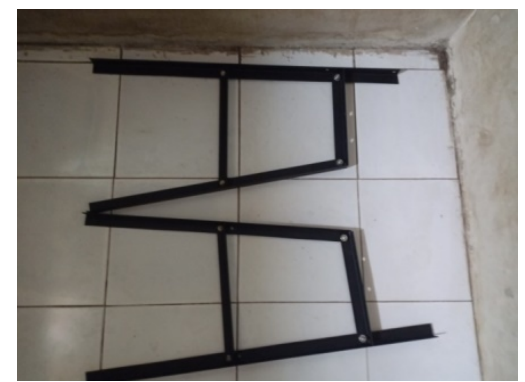

Gambar 11. Kaki Kiri dan Kanan

c. Penggabungan Part

Setelah Kaki samping belakang sudah terpasang komponennya, selanjutnya penggabungan dengan besi siku dengan ukuran 1300mm dengan menggunakan kunci pas uk.14.

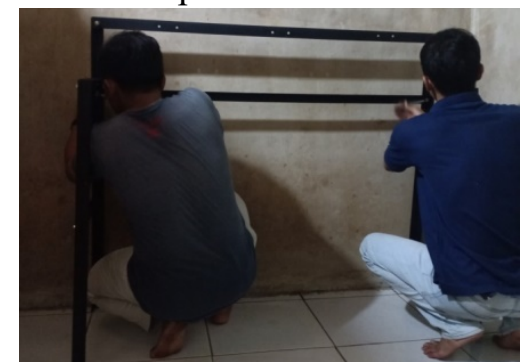

Gambar 12. Pemasangan Penghubung Kaki Kanan dan Kiri

d. Pamasangan bearing

Pemasangan bearing dengan menggunakan kunci pas uk. 14

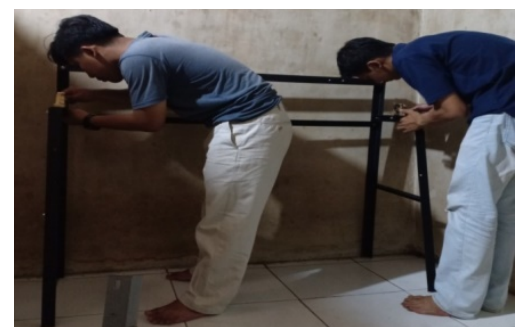

Gambar 13. Proses Pemasangan Bearing

e. Pemasangan penyangga As stang Cons

Pemasangan As dengan ukuran Dia. $18 \mathrm{~mm}$ dan panjang $1200 \mathrm{~mm}$ dengan menggunakan kunci pas uk.14 dan kunci uk. L 6

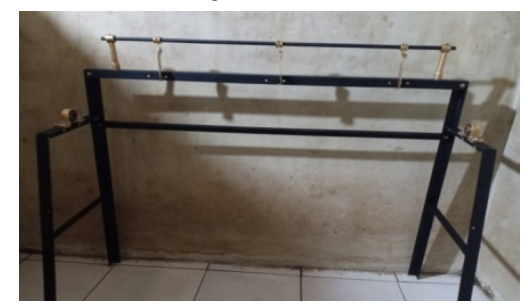

Gambar 14. Pemasangan Penyangga As Stang Cons f. Pemasangan Stang Cons

Pemasangan Stang cons menggunakan kunci pas 12

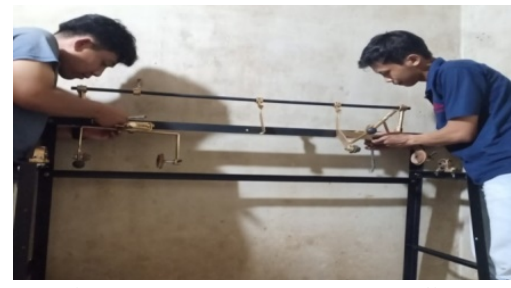

Gambar 15. Proses Pemasangan Stang Cons g. Pemasangan Bonet

Pemasangan Bonet menggunakan Kunci L uk. 3mm.

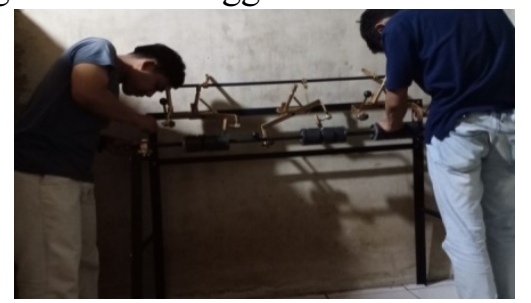

Gambar 16. Proses Pemasangan Bonet

h. Pemasangan Siku dudukan pengarah jalur benang Pemasangan siku menggunakan kunci pas uk.14.

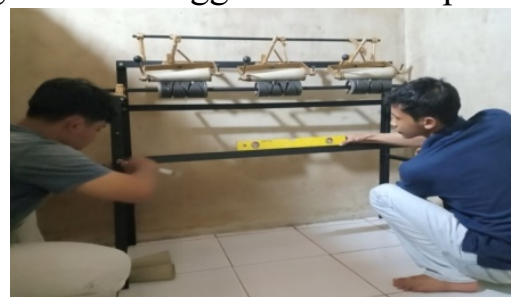

Gambar 17. Proses pemasangan pengarah benang i. Pemasangan Dudukan motor listrik Pemasangan dudukan dinamo menggunakan Kunci pas uk.12.

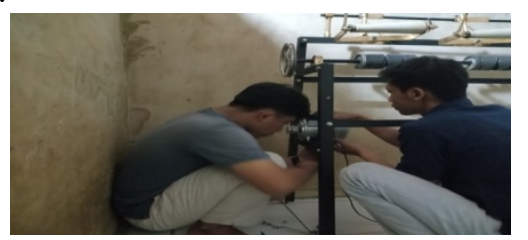

Gambar 18. Proses Pemasangan Dudukan Motor Listrik

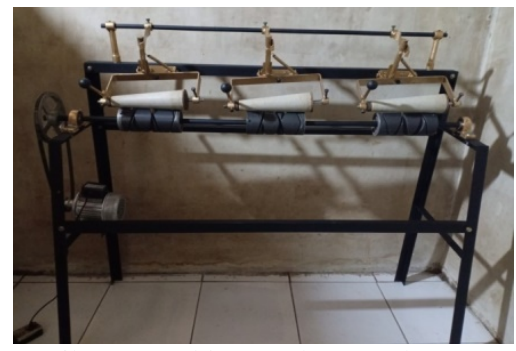

Gambar 19. Mesin Pemintal

\section{HASIL DAN PEMBAHASAN}

3.1 Analisa dan perhitungan mesin pemintal benang kapasitas 3 Cons

Berikut merupakan hasil analisa dan perhitungan beban pada kerangka mesin pemintal benang kapasitas 3 Cons:

1. Momen gaya 


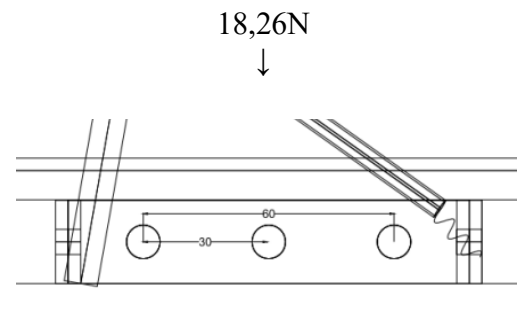

Gambar 20. Momen Gaya

$$
\begin{aligned}
\mathrm{F} & =\mathrm{m} \cdot \mathrm{g} \\
& =1,863 \cdot 9,8 \\
& =18,26 \mathrm{~N} \\
\mathrm{Fx} & =\mathrm{F} \cos 90^{\circ} \rightarrow \mathrm{Fx} \\
& =18,26 \cdot \cos 90^{\circ} \\
& =0 \mathrm{~N} \\
\mathrm{Fy} \quad & =\mathrm{F} \sin 90^{\circ} \rightarrow \mathrm{Fy} \\
& =18,26 \cdot \sin 90^{\circ} \\
& =18,26 \mathrm{~N}
\end{aligned}
$$

2. Keseimbangan Statis

$$
\begin{aligned}
& \begin{aligned}
& \text { Fy }= 18,26 \rightarrow \quad \text { RHA }=0 \text { (Tidak ada aksi) }, \\
& \text { karena tidak bergeser }
\end{aligned} \\
& \begin{aligned}
\text { Fx }= & 0 \rightarrow \text { RVA }+ \text { RVB }-\mathrm{F} \\
\text { RVA } & =\frac{\mathrm{b}}{\mathrm{L}} . \mathrm{F} \\
& =\frac{30}{60} \cdot 18,26 \\
& =9,13 \mathrm{~N}
\end{aligned}
\end{aligned}
$$

$$
\begin{aligned}
\mathrm{RVB} & =\frac{\mathrm{F}(\mathrm{N})}{\mathrm{L}(\mathrm{mm})} \\
& =\frac{18,26(\mathrm{~N})}{60(\mathrm{~mm})} \\
& =0,3 \mathrm{~N} / \mathrm{mm}
\end{aligned}
$$

$\mathrm{Fx}=0 \rightarrow \mathrm{RVA}+\mathrm{RVB}-\mathrm{F}$

$$
9,13+0,3-18,26=8,86 \mathrm{~N} / \mathrm{mm}
$$

Jadi, keseimbangan statisnya adalah

$$
\begin{aligned}
& \text { F . a - RVB . L } \\
= & 18,26 \cdot 30-0,3 \cdot 60 \\
= & 547,8-18 \\
= & 529,8 \mathrm{~N} / \mathrm{m}
\end{aligned}
$$

3. Kekuatan Beban Baut

Diketahui:

$$
d_{0}=8 \mathrm{~mm} \text { (M8) }
$$

$d_{i}=6,466 \mathrm{~mm}=0,646 \mathrm{~cm}$ (Dari table baut diperoleh )

Jawab:

$$
\mathrm{F}=\frac{\pi}{4} d_{i}{ }^{2} \cdot \sigma
$$

Gaya awal baut :

$$
\begin{aligned}
\mathrm{F} & =284 . d_{0} \\
& =284 .(8)=2272 \mathrm{Kg}
\end{aligned}
$$

Beban pada baut:

$$
\mathrm{F}=\frac{\pi}{4} d_{i}{ }^{2} \cdot \sigma
$$

$$
\begin{aligned}
22280,709 & =\frac{3,14}{4}(0,646)^{2} . \sigma \\
22280,709 & =0,785(0,417316) \cdot \sigma \\
\sigma & =68006,039 \mathrm{~N} / \mathrm{Cm}=6800,604 \mathrm{~N} / \mathrm{m} \\
& =22280,709 \mathrm{~N}
\end{aligned}
$$

4. Tahanan berat dengan momen puntir pully

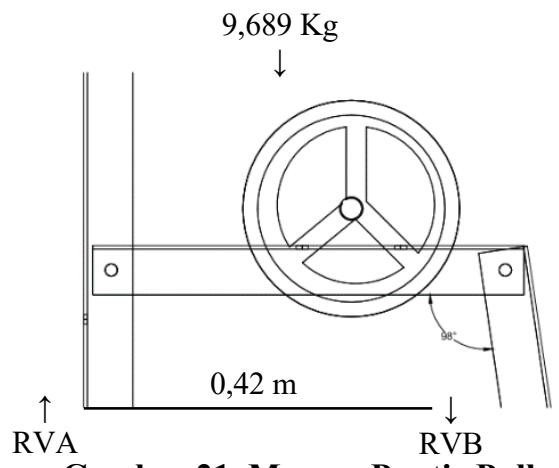

Gambar 21. Momen Puntir Pully

$$
\begin{aligned}
\mathrm{RVA} & =\frac{\mathrm{m}}{\mathrm{L}} \quad \mathrm{RVB} & & =\frac{\mathrm{m}}{\mathrm{L}} \\
& =\frac{9,689(\mathrm{Kg})}{0,42(\mathrm{~m})} & & =\frac{9,689(\mathrm{Kg})}{0,42(\mathrm{~m})} \\
& =23,069 \mathrm{Kg} / \mathrm{m}(\uparrow) & & =-23,069 \mathrm{Kg} / \mathrm{m}
\end{aligned}
$$

$(\downarrow)$

Kekuatan Beban Baut

Diketahui:

$d_{0}=10 \mathrm{~mm}$ (M10)

$d_{i}=8,160 \mathrm{~mm}=0,8160 \mathrm{~cm}$ (Dari table baut diperoleh)

Jawab:

$$
\begin{aligned}
& \mathrm{F}=\frac{\pi}{4} d_{i}{ }^{2} \cdot \sigma \\
& \text { Gaya awal baut }: \\
& \mathrm{F}=284 \cdot d_{0} \\
&=284 \cdot(10)=2840 \mathrm{Kg} \\
&=27850,886 \mathrm{~N}
\end{aligned}
$$

Beban pada baut:

$$
\begin{gathered}
\mathrm{F}=\frac{\pi}{4} d_{i}{ }^{2} \cdot \sigma \\
27850,886=\frac{3,14}{4}(0,8160)^{2} \cdot \sigma \\
\sigma \quad=53283,717 \mathrm{~N} / \mathrm{Cm}=5328,371 \mathrm{~N} / \mathrm{m}
\end{gathered}
$$

5. Tahanan berat dengan momen puntir motor listrik

Dengan massa dinamo listrik $1,7 \mathrm{Kg}$ dan massa total kerangka $24,4 \mathrm{Kg}$ 


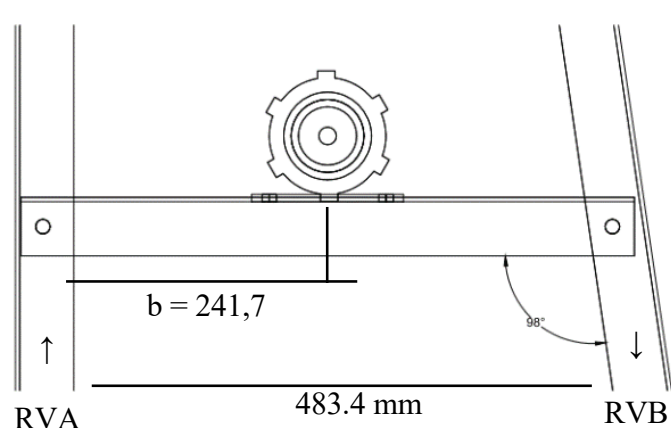

Gambar 21. Momen Puntir Listrik

$\mathrm{F} \quad=\mathrm{m} \cdot \mathrm{g}$

$=24,4 \cdot 9,8$

$=239,12 \mathrm{~N}$

RHA $=$ Reaksi Horizontal A

RVA $=$ Reaksi Vertikal A

RVB $=$ Reaksi Vertikal B

$\mathrm{RVA}=\frac{\mathrm{b}}{\mathrm{L}} \cdot \mathrm{F}$

$=\frac{241,7}{483,4} \cdot 239,12=119,56 \mathrm{~N}$

$$
\begin{aligned}
\mathrm{RVB} & =\frac{\mathrm{F}(\mathrm{N})}{\mathrm{L}(\mathrm{mm})} \\
& =\frac{239,12}{483,4}=0,494 \mathrm{~N} / \mathrm{mm}
\end{aligned}
$$

6. Kekuatan Beban Baut

Diketahui:

$$
d_{0}=8 \mathrm{~mm} \text { (M8) }
$$

Dari table baut diperoleh $d_{i}=6,466 \mathrm{~mm}=0,646$ $\mathrm{cm}$

Jawab:

$$
\mathrm{F}=\frac{\pi}{4} d_{i}{ }^{2} \cdot \sigma
$$

Gaya awal baut :

$$
\begin{aligned}
\mathrm{F} & =284 . d_{0} \\
& =284 .(8)=2272 \mathrm{Kg} \\
& =22280,709 \mathrm{~N}
\end{aligned}
$$

Beban pada baut:

$$
\begin{aligned}
\mathrm{F} & =\frac{\pi}{4} d_{i}{ }^{2} \cdot \sigma \\
22280,709 & =\frac{3,14}{4}(0,646)^{2} \cdot \sigma \\
22280,709 & =0,785(0,417316) \cdot \sigma \\
\sigma \quad & =68006,039 \mathrm{~N} / \mathrm{Cm}=6800,604 \mathrm{~N} / \mathrm{m}
\end{aligned}
$$

7. Momen inersia (momen puntir)

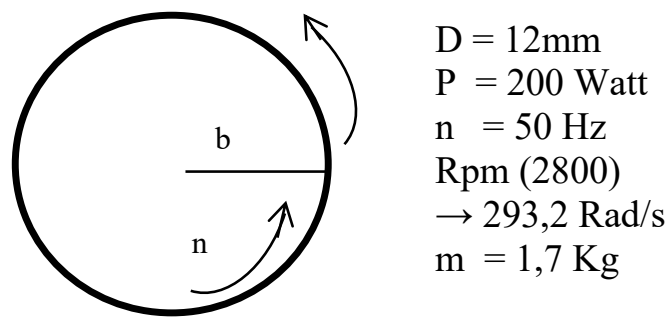

$$
\begin{aligned}
\mathrm{T} & =\frac{\text { Gambar 22. }}{2 \cdot \mathrm{P} \cdot \mathrm{n}} \\
= & \frac{60.200}{2 \cdot 3,14 \cdot 2800}=0,68 \mathrm{~N} / \mathrm{m} \rightarrow 680 \mathrm{~N} / \mathrm{mm}
\end{aligned}
$$

8. Reaksi Kontruksi

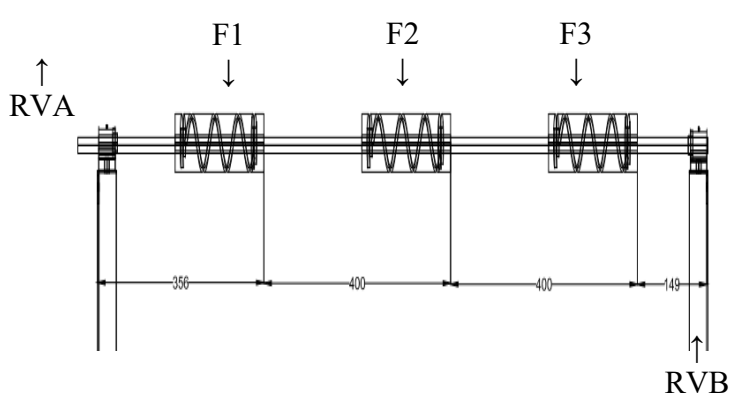

Gambar 23. Reaksi Kontruksi

$$
\begin{aligned}
\mathrm{m} 1 & =3,6 \mathrm{Kg} \\
\mathrm{m} 2 & =2,5 \mathrm{Kg} \\
\mathrm{m} 3 & =3,2 \mathrm{Kg} \\
\mathrm{F}= & \mathrm{m} \cdot \mathrm{g} \\
\mathrm{F} 1 & =\mathrm{m} \cdot \mathrm{g} \\
& =3,6 \cdot 9,8=35,28 \mathrm{~N} \\
& =0,035 \mathrm{KN} \\
\mathrm{F} 2 & =\mathrm{m} \cdot \mathrm{g} \\
& =2,5 \cdot 9,8=24,5 \mathrm{~N} \\
& =0,024 \mathrm{KN} \\
\mathrm{F} 3 & =\mathrm{m} \cdot \mathrm{g} \\
& =3,2 \cdot 9,8=31,36 \mathrm{~N} \\
& =0,031 \mathrm{KN} \\
\mathrm{RVA} & =\frac{(\mathrm{F} 1 \cdot \mathrm{L} 2)-(\mathrm{F} 2 \cdot \mathrm{L} 3)-(\mathrm{F} 3 \cdot \mathrm{L} 3+\mathrm{L} 4)}{9} \\
& =\frac{(35,28 \cdot 400)-(24,5 \cdot 400)-(31,36 \cdot 400+149)}{9} \\
& =\frac{14112-9800-12693}{9}=-8381 \mathrm{~N} / \mathrm{mm}(\downarrow) \\
\mathrm{RVB} & =\frac{(\mathrm{F} 1 \cdot \mathrm{L} 1)+\mathrm{F} 2+\mathrm{F} 3}{9} \\
& =\frac{(35,28 \cdot 356)+24,5+31,36}{9} \\
& =\frac{12559,68+24,5+31,36}{9}=1401,75 \mathrm{~N} / \mathrm{mm}(\uparrow)
\end{aligned}
$$




\subsection{Anggaran biaya}

Total biaya pembuatan alat:

1. Material dan Sparepart = Rp. 1.675 .000

2. Asseris Pelengkap = Rp. 455.000

3. Biaya Listrik $=$ Rp. 20.000

\section{KESIMPULAN}

Dari hasil penelitian yang dilakukan dapat diambil kesimpulan sebagai berikut:

1. Dari penelitian diatas dapat diketahui bahwa tahapan tahapan dari pembuatan mesin pemintal benang yaitu, (a) Mendesain gambar mesin, (b) Proses pemotongan (c) Proses pembuatan lubang baut, (d) Proses pengecatan (e) Proses perakitan mesin, (f) analisa perhitungan.

2. Didapatkan hasil dari analisis dan dan perhitungan, besar momen gaya sebesar $18,26 \mathrm{~N}$, Keseimbangan statis sebesar $529,8 \mathrm{~N} / \mathrm{m}$, kekuatan beban baut dengan ukuran M8 X 10 sebesar 22280,709 N/m untuk beban kerangka atas, $6800,644 \mathrm{~N} / \mathrm{m}$ untuk beban kerangka bawah dan M10 35 sebesar 53283,717 N/m, RVA pada tahanan berat dengan momen puntir pully adalah $23,069 \mathrm{Kg} / \mathrm{m}(\uparrow)$ dan RVB adalah $-23096 \mathrm{Kg} / \mathrm{m}$ $(\downarrow)$, momen inersia yang terjadi sebesar $680 \mathrm{~N} / \mathrm{m}$ dan Reaksi kontruksi yang terjadi RVA 8381 $\mathrm{N} / \mathrm{mm}$ dan RVB adalah $1401,75 \mathrm{Kg} / \mathrm{m}$.

3. Setelah pembuatan selesai biaya total yang harus dikeluarkan sebesar Rp. 2.150.000

Jadi, Mesin pemintal dengan kapasitas 3 cons selain mudah dibongkar pasang dan memiliki kapasitas lebih banyak juga memiliki kekuatan beban yang lebih tinggi dibanding dengan mesin pemintal yang sebelumnya yang hanya berkapasitas 2 cons dan memiliki kerangka yang bersifat pemanen.

\section{DAFTAR PUSTAKA}

Achmad, Mulia, dkk. 2018. Rancang Bangun Prototip Mesin Benang Bulky Portabel dengan Roda Gigi Crimp. Jurnal Teknik Tekstil. 33(2): 6566.

Angky, Agus, dkk. 2017. Corrective Mintenance Bearing On Rooling Machine of $1^{\text {st }}$ And $2^{\text {nd }}$ Creapper Jumbo. Jurnal Teknik Mesin. 3(2): 45.

Dedy Irwanto. 2014. Rancang Bangun Mesin Penumbuk Sagu Ubi Kapasitas 2kg/15 Menit Pada Proses Pembuatan Adonan Beras Aruk Menggunakan Metode Verien Deutche Ingenieur 2222. Jurnal Teknik Industri. 8(2): 276-286.
Denny, Jacob, dkk. 2019. Penggunaan Motor Sinkron Tiga Phase Tipe Salient Pole sebagai Generator Sinkron, Jurnal Teknik Elektro. 9(2): 198

Ragil Bayu S. 2016. Implementasi Model Pembelajaran Langsung Menggunakan Software AutoCAD Pada Kompetensi Dasar Menggambar Rencana Instalasi Penerangan Di Smk Raden Patah Mojokerto. Jurnal Teknik Elektro. 5(3): 953.

Yuntari Purba S. 2017. Rancang Bangun Aplikasi Penjualan persediaan Obat pada Apotek Merben di Kota Pramulih. Jurnal Sistem Informasi dan Komputerisasi Akuntansi. 1(1): 83.

Alex Dwi A. 2010. Rancang Bangun dan Perbaikan Mesin Bor Pertabel dan Uji Unjuk Kerja dengan Bahan Besi Tuang ST 40 dan Besi Tuang ST 60. Tugas Akhir. Semarang. Universitas Diponegoro.

Arifin Eko N, 2011. Analisis Pengendalian Kualitas Benang Polyester $100 \%$ pada Bagian Winding PT. Delta Dunia Textile Karangaanyar, Tugas Akhir. Surakarta. Universitas Sebelas Maret.

Bahar Ihsan Z. 2018. Rancang Bangun Mesin Pencacah Botol Plastik Kapasitas $35 \mathrm{Kg} / \mathrm{Jam}$. Skripsi. Tangerang. Universitas Muhammadiyah Tangerang.

Burhannuding Anas T. 2014. Pengaruh Lebar V-Belt terhadap Konsumsi Bahan Bakar pada Sepeda Motor Yamaha Mio Soul Tahun Muhammad Saleh Simamora. Perancangan Alat Uji Prestasi Turbin Pelton. Jurnal Teknik Mesin, Universitas Pasir Pangaraian.

Paryatmo Wibowo. 2007. Turbin Air. Yogyakarta; Graha Ilmu

Prihastuty Endang, Heru Dwi Fahmadi. Perancangan Nossel dan Sistem Perpipaan Pada Turbin Pelton.Jurnal Teknik Mesin, Universitas 17 Agustus 1945 Cirebon, Vol 10 No 1 April Tahun 2015, 10-17.

Septiadi Rully. Optimasi Desain Turbin Pelton Menggunakan 3 Nozzle Dan Variasi Kemiringan Sudu Hingga 150 Menggunakan Metode Taguchi. Jurnal Ilmiah TEKNOBIZVol. 9 No. 1.

Setiawan Parta - Pengertian Energi, Perubahan, Bentuk, Sifat, Fungsi - Kamis, 13 Agustus 2020 -

https://www.gurupendidikan.co.id/penge rtian-energi/ 